\title{
Learning Styles of Students at the Department of Computer Science - University of Potsdam
}

\author{
Loay Talib Ahmed Al-Saffar \\ Computer Science Dept., University of Potsdam, \\ Germany and College of Electrical and Electronic Techniques, Baghdad, Iraq \\ alsaffar.loay@gmail.com
}

\begin{abstract}
This paper is part of a research to understand the learning style preferences of students at the computer science department - University of Potsdam, to be aware of which changes are necessary to be adopted in the teaching methods, in an attempt to make an impact on reducing the dropout rate among students, and to suggest a better learning environment meeting most of the students' learning style preferences. It will present and discuss initial results of using the Index of Learning Styles (ILS) questionnaire developed by Felder and Soloman, which is a 44-item questionnaire for identifying the learning styles according to Felder-Silverman learning style model FSLSM.
\end{abstract}

Keywords: Learning Styles, Felder-Silverman learning style model, Computer Science, Business Informatics, and Didactics.

\section{Introduction}

It is generally agreed that different learning styles exist and there is a general acceptance that the manner "in which individuals choose to or are inclined to approach a learning situation" has an impact on performance and achievement of learning outcomes [1]. So incorporating learning styles in teaching plans may make learning easier and leads to better achievement [2]. Researchers have developed many different models for identification of learning styles. In general, a learning style model classifies students according to where they fit on a number of scales pertaining to the ways they receive and process information [3].

There are several different learning style models. In this paper, the FelderSilverman learning style model (FSLSM) is used; most other learning style models classify learners into a few groups, whereas Felder and Silverman describe the learning style of a learner in more detail, distinguishing between preferences in four dimensions. It is based on tendencies, indicating that learners with a high preference for certain behaviour can also act sometimes differently [2].

According to FSLSM, each learner has a preference on four distinct dimensions: active/reflective (ACT/REF), sensing/intuitive (SEN/INT), visual/verbal (VIS/VER), and sequential/global (SEQ/GLO). Active learners learn by trying things out and working together with others, whereas reflective learners learn by thinking things through and reflecting about them, and they prefer to learn alone. Sensing learners like to learn from concrete material like examples, tend to be more practical, and are careful 
with details, whereas intuitive learners prefer to learn abstract material, like challenges, and are more innovative. Visual learners remember best what they have seen, whereas verbal learners get more out of words, regardless whether they are spoken or written. Sequential learners learn in linear steps, prefer to follow linear, stepwise paths and be guided through the learning process, whereas global learners learn in large leaps and prefer a higher degree of freedom in their learning process $[3,4,5,6]$.

The Index of Learning Styles (ILS), created by Felder and Soloman, is a questionnaire for identifying the learning styles according to FSLSM, where 11 questions are assigned for each dimension. Each question has two answer choices and the respondent should pick the most suitable one. Each choice represents a preference on a dimension. The preference that scores higher is the dominant preference in that dimension and the difference in scores indicates the strength of the preference. When a dimension is in balance, meaning that the score is between -3 and 3, a student can switch between the preferences depending on the teaching style. In practice this means that no matter which preference is used in teaching, such students will manage. The students that need the teacher's attention are those whose preference is moderate or strong (meaning that the score is between -5 and -11 or between 5 and 11). The more students in that category, the more a teacher should adapt the teaching to meet their needs $[4,5,6]$.

The main goal of this research is to understand the learning style preferences of students at the computer science department - University of Potsdam, and look into the differences between students of different study fields at the department who usually take some joint courses.

\section{Methodology}

Participants were a volunteer sample of students of the computer science department at the University of Potsdam, 135 students covering every academic semester with different study specialties (42\% Computer Science, 34\% Business Informatics, 16\% Teaching Computer Science, and $8 \%$ other specialties) participated in filling the ILS questionnaire (A multiple choice questionnaire, see [7]), 116 students filled the questionnaire electronically while 19 students filled a hard copy. 45 female students (33\%) and 90 male students (67\%) participated in the research. (Figure 1 shows the number of the students participating in the research according to gender in each specialty and figure 2 shows the number of students from each semester).

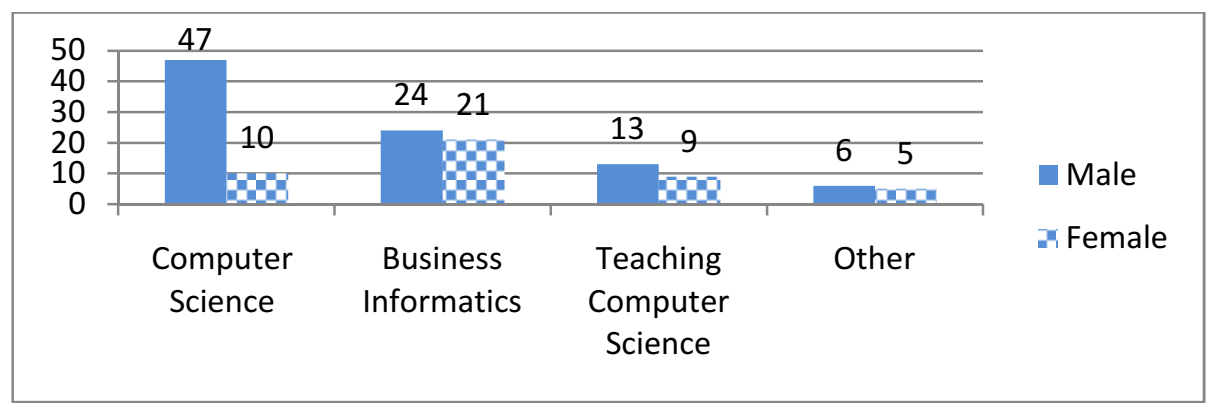

Fig. 1. Number of the students according to gender of each specialty 


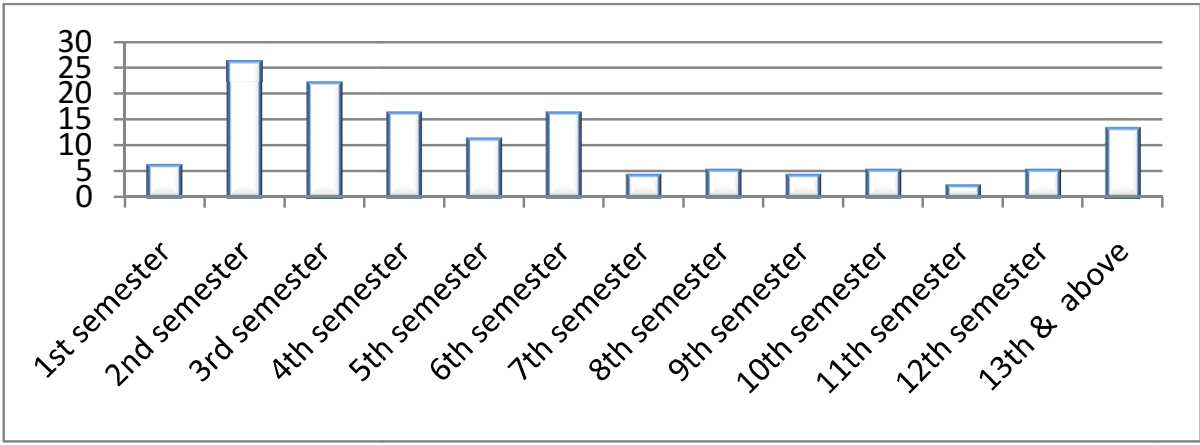

Fig. 2. Number of students from each semester

\section{Results and Discussion}

From figure 3 which shows the preference of all students one can see that students are more active, sensing and visual while more balanced for the sequential/global dimension. The results, for each of the specialties: computer science, business informatics, and teaching computer science and according to gender are discussed below.

\section{Active/Reflective (ACT/REF) Dimension}

Figure 4A shows that female business informatics students are more active learners than the computer science female students, and both of them have no moderate or strong preference towards being a reflective learner. Male students (computer science and business informatics) are more divided between being "moderate or strong active learners" and being "balanced".

The male teaching computer science students are balanced, while the female students have tendency towards being more active learners, see figure $5 \mathrm{~A}$.

\section{Sensing/Intuitive (SEN/INT) Dimension}

Figure 4B shows that female students (computer science and business informatics) are more sensing learners, while male students (computer science and business informatics) are more balanced with none of the business informatics students being moderate or strong intuitive learners.

The male teaching computer science students are more balanced, and having tendency of being intuitive learner, while the female students are more sensing, see figure 5B.

\section{Visual/Verbal (VIS/VER) Dimension}

Figure $4 \mathrm{C}$ and figure $5 \mathrm{C}$ show that most students are between balanced and moderate visual learners, with computer science students having a little bit more tendency towards being strong visual learners, especially the male students, and the male teaching computer science students share the same tendency. 


\section{Sequential/Global (SEQ/GLO) Dimension}

Figure 4D and figure 5D show that most of the students are balanced, but computer science students have a little bit more tendency towards being global learners and the business informatics students have a little bit more tendency towards being sequential learners.

\section{Students Opinion}

Students who had provided us with a valid email address were sent the personal learning styles results of the first questionnaire together with a second questionnaire to ask them whether they agree with the results they had received. $19 \%$ of them responded, see figure 6 . Most of them agreed with the results, but in the sensing/intuitive (SEN/INT) dimension students had the biggest doubts whether the results matched their real learning style!

Students who filled a hard copy of the questionnaire (19 students; 9 females and 10 males. 17 of them were business informatics and 2 other computer science students) were asked directly afterwards to give their opinion about their own learning style preferences before giving them the results of the questionnaire. First the students were introduced to each dimension and then they gave their opinion. There were 7 major mismatches for the active/reflective (ACT/REF) dimension (6 male students thought that they are more verbal or balanced while the result of the ILS questionnaire classified them as visual learners), 5 mismatches for the sensing/intuitive (SEN/INT) dimension (4 students predicted to be moderate sensing learners but the result showed them as more balanced), 3 mismatches for the active/reflective (ACT/REF) dimension, and 1 major mismatch for the sequential/global (SEQ/GLO) dimension.

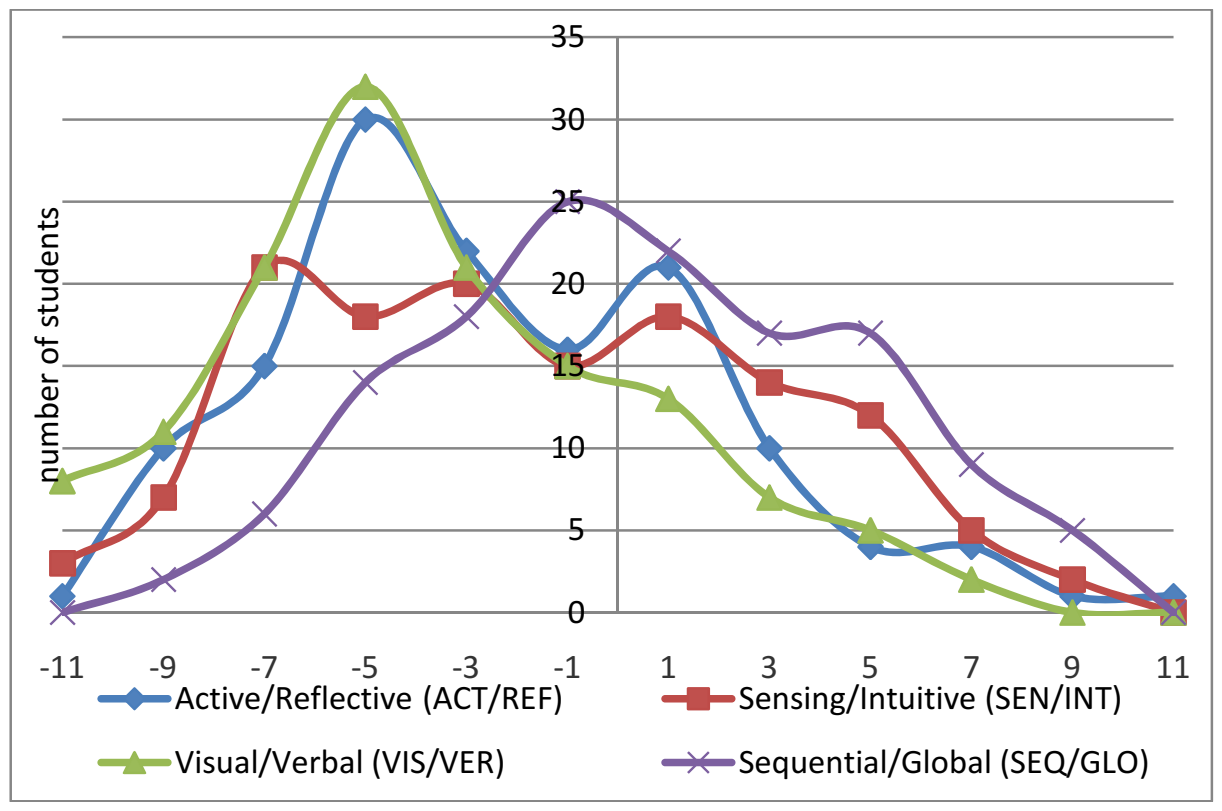

Fig. 3. All four dimensions distribution of the students learning styles 


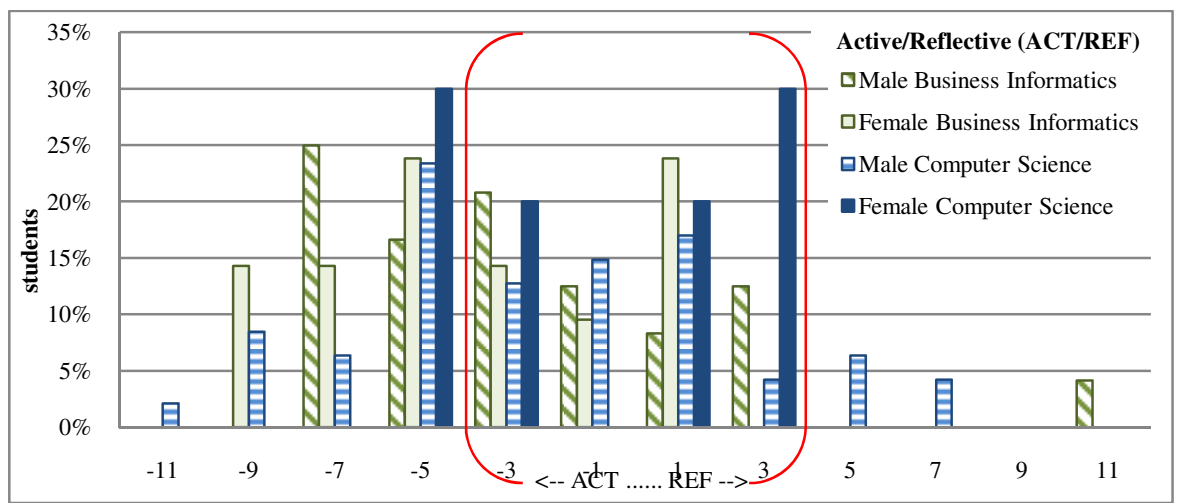

Fig. 4A

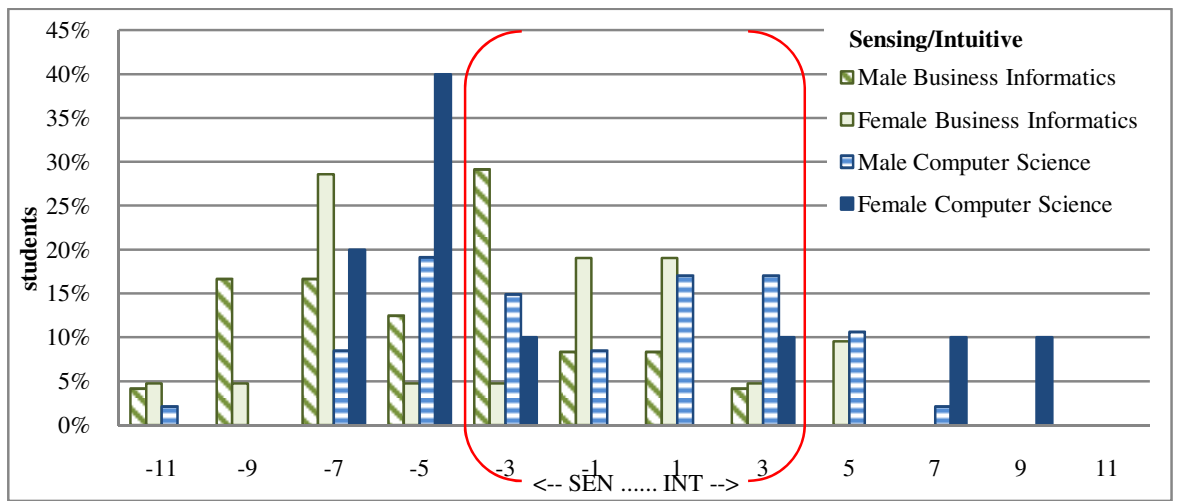

Fig. 4B

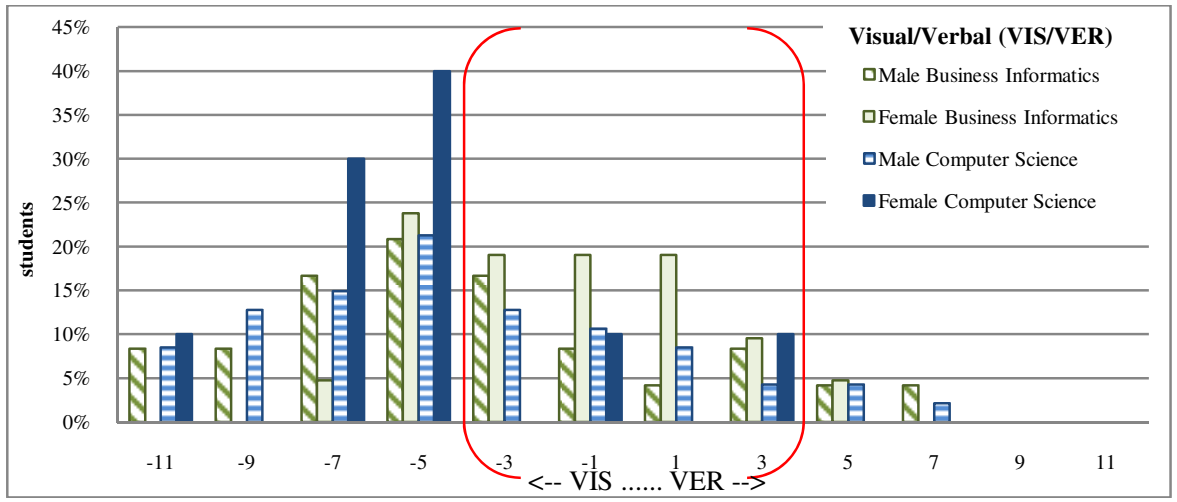

Fig. 4C

Fig. 4. A, B, C and D: All four dimensions distribution of the Business Informatics and Computer Science students, distinguishing between genders 


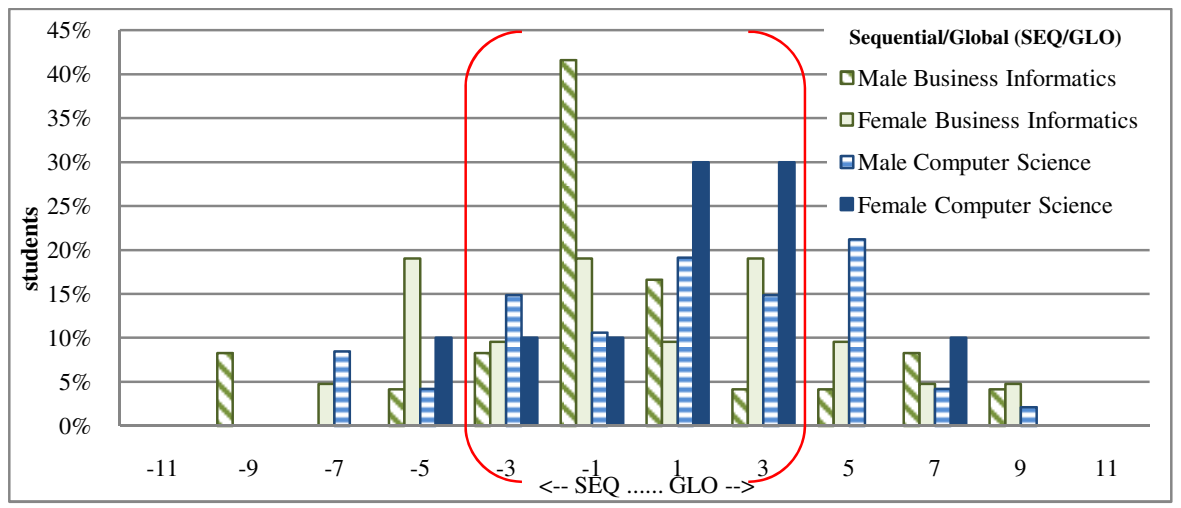

Fig. 4D

Fig. 4. (Continued)
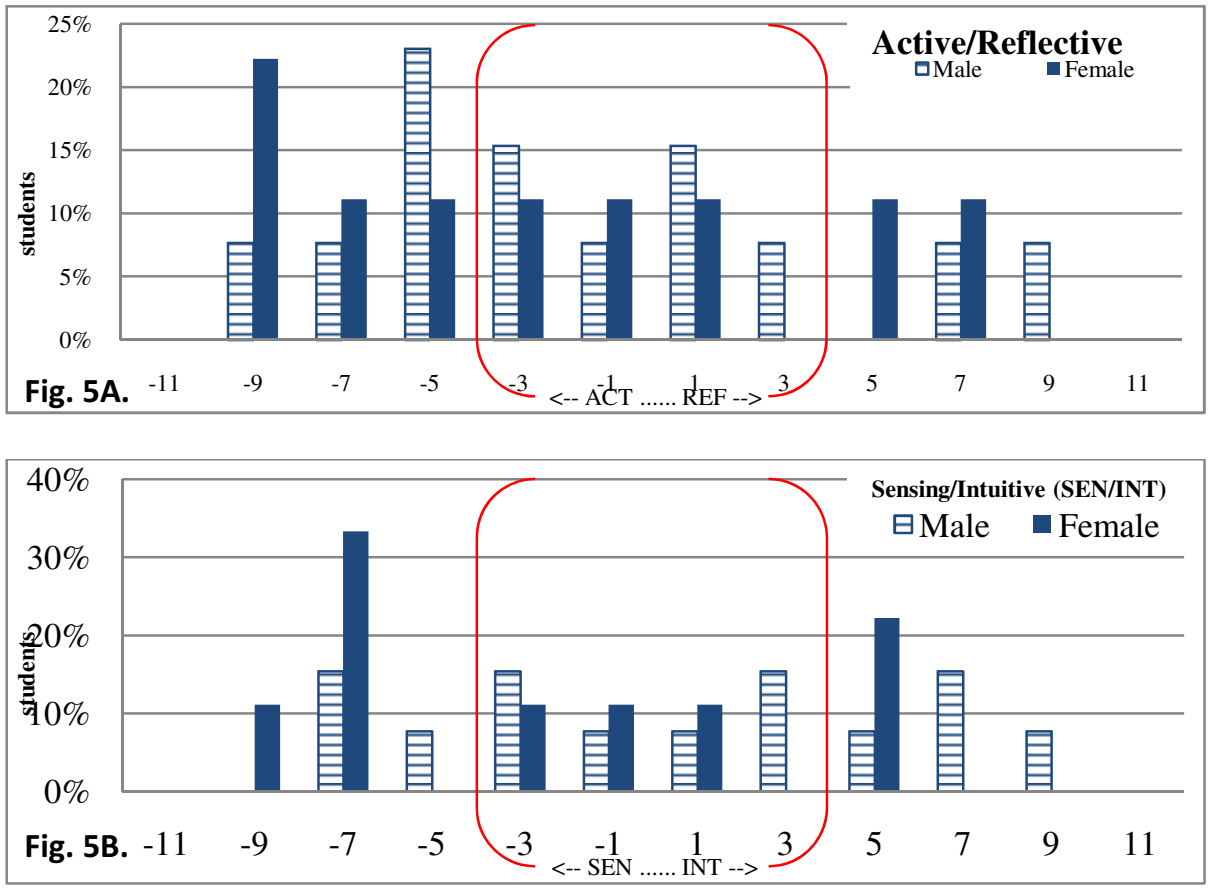

Fig. 5. A, B, C and D: All four dimensions distribution of the teaching computer science students, distinguishing between genders 

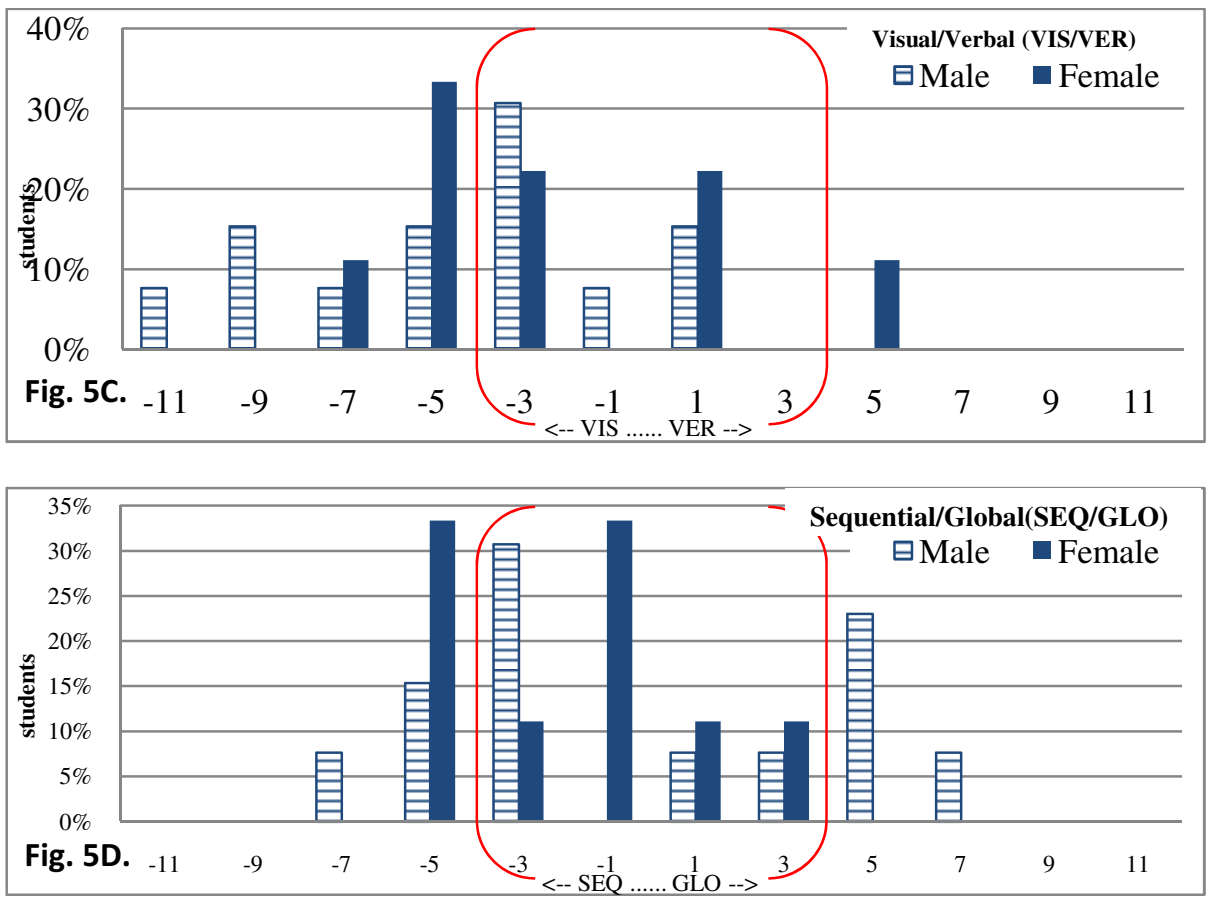

Fig. 5. (Continued)

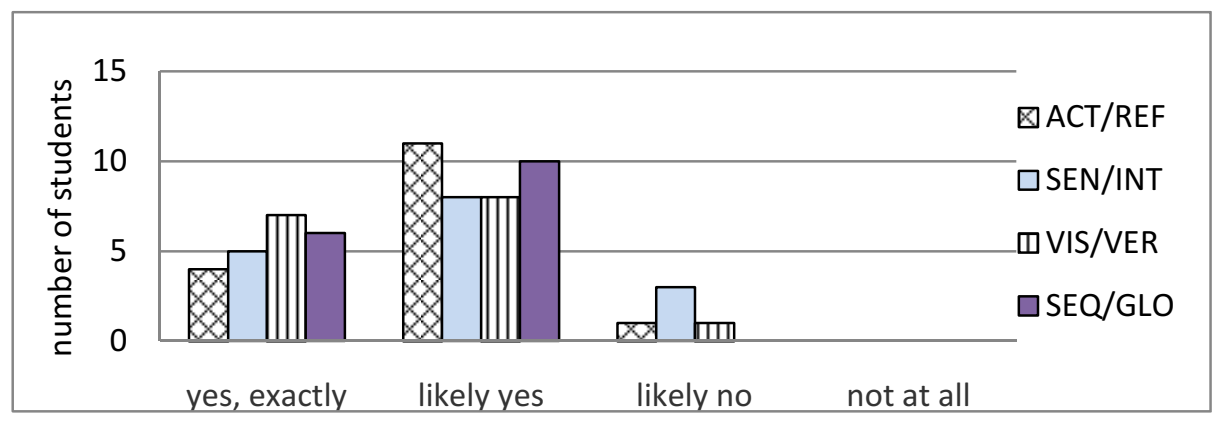

Fig. 6. Students opinion about the results

\section{Conclusions}

By using the Index of Learning Styles (ILS) questionnaire developed by Felder and Soloman, one can notice differences in the preferences of learning style between male and female students of different study fields at the computer science department, as well as differences between students with different specialties, for example: 'female business informatics students are more active learners than the computer science 
female students. Computer science students have a little bit more tendency towards being strong visual learners, especially the male students. Male students (computer science and business informatics) are more balanced with none of the business informatics students being moderate or strong intuitive learners, while the male teaching computer science students have tendency of being intuitive learner. And the computer science students have a little bit more tendency towards being global learners while the business informatics students have a little bit more tendency towards being sequential learners.'

Further research should be conducted in this area to look into these differences in a way that reflects positively on the teaching methods of the subjects that embrace all those students who might differ in the way they learn. More investigation in the ILS questionnaire should also be adopted to overcome some of the problems in distinguishing learning styles, for example the visual/verbal (VIS/VER) dimension.

Acknowledgment. I would like to thank Prof. Dr. Andreas Schwill for his advice, help and support.

\section{References}

1. Cassidy, S.: Learning Styles: An overview of theories, models, and measures. Educational Psychology 24(4) (2004)

2. Graf, S., Viola, S.R., Leo, T.: Kinshuk: In-Depth Analysis of the Felder-Silverman Learning Style Dimensions. Journal of Research on Technology in Education (2007)

3. Alaoutinen, S., Smolander, K.: Are Computer Science Students Different Learners? In: Proceedings of the 10th Koli Calling International Conference on Computing Education Research, Finland (2010)

4. Derntl, M., Graf, S.: Impact of Learning Styles on Student Blogging Behavior. In: Ninth IEEE International Conference on Advanced Learning Technologies (2009)

5. Felder, R.M., Spurlin, J.: Applications, reliability and validity of the Index of Learning Styles. International Journal on Engineering Education 21 (2005)

6. Soloman, B.A., Felder, R.M.: Learning Styles and Strategies (1993), http://www4 . ncsu.edu/unity/lockers/users/f / felder/public/ILSdir/ILS.pdf,

Felder, R.M., Silverman, L.K.: Based on Material, Learning and Teaching Styles in Engineering Education. Engr. Education, 78(7), 674-681 (1988)

7. Soloman, B.A., Felder, R.M.: Index of Learning Styles Questionnaire, http://www . engr.ncsu. edu/learningstyles/ilsweb.html 